\title{
An in situ investigation of the deformation mechanisms in a $\beta$-quenched Ti-5Al-5V-5Mo-3Cr alloy
}

\author{
Pere Barriobero-Vilaa, b, *, Joachim Gussone ${ }^{\mathrm{a}}$, Klemens Kelmª, Jan Haubrich ${ }^{\mathrm{a}}$, Andreas Stark ${ }^{\mathrm{c}}$, Norbert Schell ${ }^{\mathrm{c}}$, \\ Guillermo Requena ${ }^{\text {a, } d}$
}

${ }^{a}$ Institute of Materials Research, German Aerospace Center (DLR), Linder Höhe, 51147 Cologne, Germany

${ }^{\mathrm{b}}$ Institute of Materials Science and Technology, Vienna University of Technology, Karlsplatz 13/308, 1040 Vienna, Austria

${ }^{c}$ Helmholtz-Zentrum Geesthacht, Max-Planck-Straße 1, 21502 Geesthacht, Germany

${ }^{\mathrm{d}}$ Metallic Structures and Materials Systems for Aerospace Engineering, RWTH Aachen University, 52062 Aachen, Germany

\section{A R T I CLE INFO}

Keywords:

$\beta$ titanium alloys

Deformation

Stress-induced martensite

Planar slip

Phase stability

In situ high energy synchrotron X-ray diffrac-

tion

\begin{abstract}
A B S T R A C T
The sequence of activation of deformation mechanisms in a near- $\beta$ Ti-5Al-5Mo-5V-3Cr alloy quenched from the $\beta$-field is investigated as a function of strain during uniaxial compression at $0.001 \mathrm{~s}^{-1}$ up to $\varepsilon=0.041$. Bulk in situ high energy synchrotron X-ray diffraction is applied to follow continuously the evolution of the microstructure of the alloy during deformation and is complemented with metallographic analysis. Stress induced $\beta \rightarrow \alpha^{\prime \prime}$ transformation takes place together with grain rotation of $\beta$ upon reaching the yield stress of the alloy at $\varepsilon=$ 0.021. During further loading, formation of $\beta$ sub-grain cells is activated at $\varepsilon \geq 0.03$. The stress-induced martensite forms with a strong texture of $\{200\} \alpha^{\prime \prime}$ planes perpendicular to the compression direction.
\end{abstract}

\section{Introduction}

$\beta$ titanium alloys - including $\beta$-rich $\alpha+\beta$ alloys, near- $\beta$ alloys and metastable- $\beta$ alloys - are primarily used in aerospace and as alternative structural materials for the automotive sector owing to their combination of high specific strength and hardening levels with acceptable toughness and fatigue resistance [1-3]. These structural properties are essentially defined by a homogeneous distribution of $\alpha / \beta$ interfaces owing to the presence of fine $\alpha$ precipitates embedded in a $\beta$ matrix. They result from solution plus aging treatments that provide high strength in detriment of ductility. The latter justifies the necessity to explore strengthening mechanisms alternative to $\alpha$ precipitation, i.e. processing routes that imply mechanical and thermal processing by utilizing the stability of $\beta$ at room temperature (RT) and the cold workability of $\beta$-alloys [4]. Such insights into the design of $\beta$ Ti-alloys can also widen their application to the biomedical sector where they are being considered for advanced implants or prostheses due to their biocompatibility and low bone-like Young's modulus $[5,6]$.

Approaches aiming at improving the strength-ductility trade-off of $\beta$ Ti-alloys have been focused on exploiting the deformation mechanisms of $\beta$ as a function of its thermal stability, namely dislocation slip, transformation duced plasticity (TRIP) and twinning induced plasticity (TWIP). Alteration of the thermal condition via diffusion-driven processes (e.g. precipitation of $\alpha$ by ageing) can hinder the occurrence of these effects [7]. Moreover, a correct knowledge of the sequence of activation of the deformation mechanisms is required owing to their relevance on the resulting mechanical behaviour [8-10]. For instance, a combination of TRIP and TWIP during deformation of metastable $\beta$ alloys can lead to improvements in strain hardening and enhanced ductility $[9,10]$. This indicates that the simultaneous or sequential activation of multiple deformation mechanisms during deformation of single- or multi-phase alloys can be used as multiple paths for alloy design as has been recently shown for systems with coexisting isothermal $\omega$ and $\beta$ phases [7]. Also, kinetic variables such as strain rate are in some cases capable of changing the sequence of activation of deformation mechanisms [11]. This has received less attention (e.g. $[10,12]$ ) although this fact constrains the development of knowledge-based processing strategies as well as theoretical predictions $[5,13,14]$ that require validation by experimental data for the design of new $\beta$-alloys.

The sequence of deformation mechanisms in $\beta$-retained Ti-alloys has been mainly discussed on the basis of atomistic studies and ex situ experiments. Although important insights have been gained in this regard (e.g. [15,16]), only in situ studies can provide conclusive proof on the mechanisms acting at each

\footnotetext{
* Corresponding author at: Institute of Materials Research, German Aerospace Center (DLR), Linder Höhe, 51147 Cologne, Germany.

Email addresses: pere.barrioberovila@dlr.de (P. Barriobero-Vila); joachim.gussone@dlr.de (J. Gussone); klemens.kelm@dlr.de (K. Kelm); jan.haubrich@dlr.de (J. Haubrich); andreas. stark@hzg.de (A. Stark); norbert.schell@hzg.de (N. Schell); guillermo.requena@dlr.de (G. Requena)
} 
stage during deformation. In the present work, the deformation mechanisms of a $\beta$-quenched near- $\beta$ Ti-5Al-5Mo-5V-3Cr alloy commonly employed in aeronautics, e.g. for landing gear components [17], are determined continuously during room temperature uniaxial compression using in situ high energy synchrotron X-ray diffraction (HEXRD). The investigations are complemented by metallographic analysis. The correlation between the crystal lattice evolution during loading/unloading and mechanisms of deformation is provided univocally as a function of strain.

\section{Experimental}

\subsection{Material}

The composition of the investigated near- $\beta$ titanium alloy Ti-5Al-5Mo-5V-3Cr (Ti-5553) manufactured by ATI is given in Table 1. The $\beta$-transus temperature $\left(T_{\beta}\right)$ ranges between 837 and $860^{\circ} \mathrm{C}$. Samples of $40 \times 30 \times 20 \mathrm{~mm}^{3}$ were cut from an as-received ingot and were subjected to an isothermal heat treatment at $900^{\circ} \mathrm{C}$ ( $\beta$-field) for $20 \mathrm{~min}$ in dynamic argon $4.6 \mathrm{~atm}$ followed by quenching in RT water. This water-quenched condition is the initial condition for the further investigations.

\subsection{Microscopy}

Metallographic examinations prior and after uniaxial compression at RT were performed using light optical microscopy (LOM), electron backscatter diffraction (EBSD) analysis and transmission electron microscopy (TEM). The specimens were prepared for LOM and EBSD examinations by grinding and polishing using a TegraPol machine. The samples for LOM were immersed for $1 \mathrm{~min}$ in a $5 \mathrm{ml} \mathrm{HF}+10 \mathrm{~g} \mathrm{H}_{2} \mathrm{C}_{2} \mathrm{O}_{4}$ $+50 \mathrm{ml} \mathrm{H}_{2} \mathrm{O}$ reagent solution at RT to reveal the microstructural constituents. LOM was carried out using a Zeiss LSM 700 laser scanning microscope in visible light mode.

For EBSD, a Zeiss Ultra 55 field emission gun scanning electron microscope (FEG-SEM) operated at $20 \mathrm{kV}$ was employed in combination with an Oxford Nordlys II EBSD detection system using the acquisition software AZtec (Version 3.3). The beam step-size, working distance and sample-tilt angle used are $2.2 \mu \mathrm{m}, 10 \mathrm{~mm}$ and $70^{\circ}$, respectively. Processing of EBSD data was carried out with the Channel 5 software.

Thin-foil specimens were prepared for TEM by electropolishing. The samples were examined with a Philips Tecnai F30 microscope operated at $300 \mathrm{keV}$.

\subsection{In situ high energy synchrotron $X$-ray diffraction}

In situ HEXRD was carried out at the P07-HEMS beamline of PETRA III, Deutsches Elektronen-Synchrotron (DESY), Hamburg [18]. The experimental parameters are summarized in Table 2. Uniaxial compression of the $\beta$ water-quenched Ti-5553 alloy was performed at RT using a modified dilatometer
Bähr 805A/D equipped with a deformation unit [19]. Cylindrical samples of $4 \mathrm{~mm}$ diameter and $8 \mathrm{~mm}$ length were deformed at a strain rate of $0.001 \mathrm{~s}^{-1}$ up to a true strain of 0.041 using colloidal graphite based lubricant and Mo foils between the $\mathrm{Si}_{3} \mathrm{Ni}_{4}$ pushrods of the dilatometer and the sample to minimize friction. The sample dimensions were limited by the maximum force of the dilatometer and no buckling failure of the samples was observed during deformation. The specimens were machined via spark wire erosion. The effect of the dilatometer stiffness on the phase's macrostrains is assumed to be negligible. The incident X-ray beam was positioned at the centre of the samples before and during deformation. Image sequences of complete Debye-Scherrer rings from the bulk of the samples were recorded in transmission mode (sample thickness $=4 \mathrm{~mm}$ ) during uniaxial compression using an image-plate detector (see Table 2). Fig. 1 is an illustrative diagram of the experimental setup.

\subsubsection{Data processing}

Qualitative analysis of the evolution of the diffraction patterns during uniaxial compression was carried out by unrolling the Debye-Scherrer rings, i.e. converting them into Cartesian coordinates (Azimuthal angle $\psi$, 2-Theta). Subsequently, two separate procedures were performed using the software ImageJ [20]:

- Projection of the maximum intensity of Bragg reflections on the 2-Theta axis.

- Projection of the maximum intensity of Bragg reflections on the Azimuthal axis.

Quantitative phase analysis of the diffraction patterns was carried out using the Rietveld method as implemented in the software Maud [21]. An E-WIMV algorithm integrated in this software was used for texture analysis. The instrumental parameters of the HEXRD setup were obtained using a $\mathrm{LaB}_{6}$ powder standard. The lattice strains in each phase were calculated parallel (axial) and perpendicular (radial) to the loading direction from 2-Theta variations of individual $\{h k l\}$ reflections considering cake portions of $10^{\circ}$ (see Fig. 1) according to:

$\varepsilon_{i}=\frac{d_{i}-d_{0}}{d_{0}}$

where $\varepsilon_{i}$ and $d_{i}$ are the strain and the interplanar distance of the lattice at the deformation step $i$, respectively. The $d$-spacing obtained for the initial condition of the alloy before deformation was used as $d_{0}$ for the $\beta$ phase. The initial $d$-spacing at the onset of $\alpha^{\prime \prime}$ formation, i.e. that obtained when $\alpha^{\prime \prime}$ reflections begin to form during deformation, was taken as $d_{0}$ for this phase. This analysis represents an incremental evaluation of the strain during deformation.

Table 1

Composition of the Ti-5Al-5Mo-5V-3Cr alloy.

\begin{tabular}{|c|c|c|c|c|c|c|c|c|}
\hline Element & Al & V & Mo & $\mathrm{Cr}$ & $\mathrm{Fe}$ & o & $\mathbf{N}$ & Sn \\
\hline wt $\%$ & 5.20 & 4.80 & 4.91 & 2.92 & 0.46 & 0.13 & 0.053 & 0.03 \\
\hline Element & $\mathrm{Cu}$ & $\mathrm{Zr}$ & $\mathbf{N i}$ & C & B & $\mathbf{Y}$ & $\mathrm{Ti}$ & {$[\mathrm{Mo}]_{\mathrm{eq}}$} \\
\hline wt\% & 0.01 & $<0.015$ & 0.01 & 0.0076 & $<0.001$ & $<0.001$ & Balance & 12.93 \\
\hline
\end{tabular}

Table 2

Experimental parameters used during the in situ HEXRD experiments.

\begin{tabular}{|c|c|c|c|c|c|c|}
\hline Beamline & $\begin{array}{l}\text { Energy } \\
{[\mathrm{keV}]}\end{array}$ & $\begin{array}{l}\text { Wavelength } \\
\text { [̊]] }\end{array}$ & $\begin{array}{l}\text { Slit-aperture/beam size } \\
{\left[\mathrm{mm}^{2}\right]}\end{array}$ & $\begin{array}{l}\text { Acquisition time [s/ } \\
\text { frame] }\end{array}$ & $\begin{array}{l}\text { Read-out time } \\
\text { [s] }\end{array}$ & Detector \\
\hline $\begin{array}{l}\text { P07-PETRA } \\
\text { III }\end{array}$ & 100 & 0.124 & $1 \times 1$ & 2 & 1 & $\begin{array}{l}\text { PerkinElmer XRD } \\
1621\end{array}$ \\
\hline
\end{tabular}




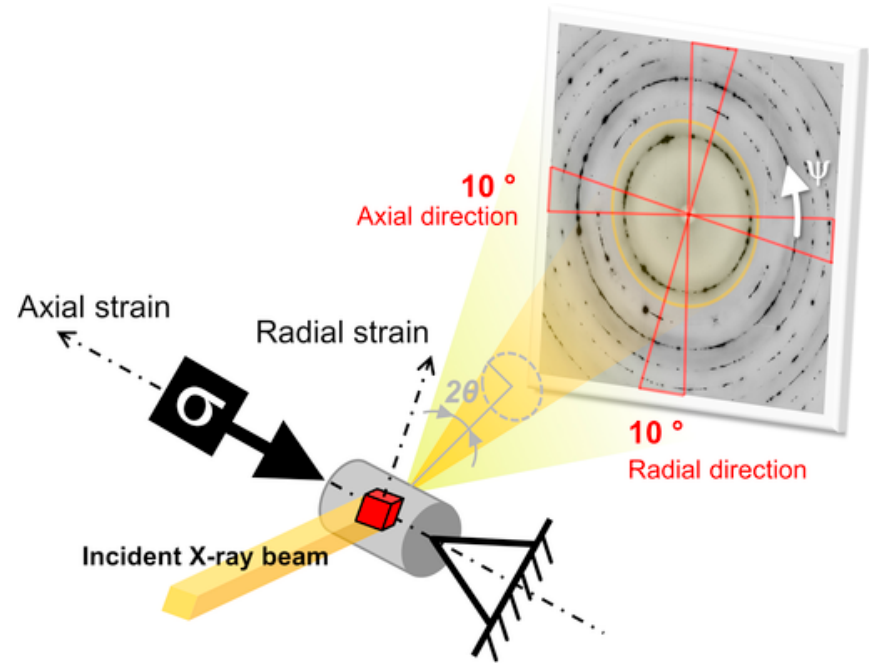

Fig. 1. Schematic representation of the experimental setup used for in situ high energy synchrotron X-ray diffraction during uniaxial compression at RT.

\section{Results}

\subsection{Initial microstructure}

Fig. 2a) shows that the initial microstructure of the Ti-5553 alloy is formed by a matrix of metastable, equiaxed $\beta$ grains with a mean diameter $\sim 350 \mu \mathrm{m}$. The selected area electron diffraction (SAED) pattern of Fig. 2b) was obtained from the interior of a $\beta$ grain. $\beta$ spots can be clearly identified together with low intensity reflections interconnected by diffuse scattering that are associated with the presence of athermal $\omega$ phase $\left(\omega_{\text {ath }}\right)$ [17]. Particles of this phase of $\sim 1$ to $2 \mathrm{~nm}$ are visible in the TEM dark field image of Fig. 2c) obtained using the (100) $\omega$ reflection indicated in Fig. 2b). No other phases such as $\alpha^{\prime \prime}$ were detected in the initial condition of the Ti-5553 alloy.

\subsection{In situ deformation during HEXRD}

Fig. 3 shows the evolution of a quarter portion of complete Debye-Scherrer rings during uniaxial RT compression as well as after unloading for $\sigma=0,700,930 \mathrm{MPa}$ and $\sigma=15 \mathrm{MPa}$, respectively. These conditions are indicated in the true stress-strain $(\sigma-\varepsilon)$ diagram shown in this figure. Before deformation, the presence of the $\beta$ reflections $\{110\}$, $\{200\},\{211\},\{220\}$ and $\{310\}$ is evident in Fig. 3a). The low number of grains in the relatively small gauge volume used during HEXRD is reflected in the discontinuous Debye-Scherrer rings obtained. The reflections $\{110\}$ and $\{200\}$ of $\alpha^{\prime \prime}$ martensite form at $\sim 700 \mathrm{MPa}$, pointing to a stress-induced $\beta \rightarrow \alpha^{\prime \prime}$ transformation during compression (Fig.
$3 \mathrm{~b})$. This stress is close to the yield stress of $720 \mathrm{MPa}$ reported for the investigated $\beta$-water-quenched condition [22]. Moreover, a local minimum in the second derivative of the $\sigma-\varepsilon$ curve is observed at this point ( $\sigma=700 \mathrm{MPa}, \varepsilon=0.021$ ) as indicated by data shown as red points and the green curve. Further compression up to the maximum deformation applied ( $\sigma=930 \mathrm{MPa}, \varepsilon=0.041$ ) results in an increase of intensity and consolidation of $\alpha^{\prime \prime}$ reflections (Fig. 3c). During unloading, a decrease of intensity of $\alpha^{\prime \prime}$ reflections can be generally observed as indicated by the arrows in Fig. 3d). Nevertheless, a fraction of the $\alpha^{\prime \prime}$ formed during deformation remains upon unloading indicating that the stress-induced $\beta$ $\rightarrow \alpha^{\prime \prime}$ transformation is only partially reversible.

Fig. 4 shows the evolution of $\{h k l\}$ reflections of $\alpha^{\prime \prime}$ and $\beta$ in the axial direction during uniaxial compression and subsequent unloading. The scale of the $x$-axis is adapted to the number of XRD images measured i.e. differs to that of Fig. 3 obtained from dilatometer data. Initially, the $\{110\},\{200\}$ and $\{211\}$ reflections of $\beta$ are present. A shift towards higher 2-theta positions occurs for the $\beta$ reflections and, thus, a consequent decrease of $d$-spacing during deformation up to $\sigma \sim 700 \mathrm{MPa} / \varepsilon \sim$ 0.021 , where plasticity becomes clear. Reflections of $\alpha^{\prime \prime}$ begin to form at this stage, coexisting with $\beta$ reflections during further compression and remaining visible upon unloading. The 2-Theta position of all presented $\alpha^{\prime \prime}$ and $\beta$ reflections decreases rapidly once the stress is released.

Fig. 5b) and c) show the evolution of the volume fractions of $\alpha^{\prime \prime}$ and $\beta$ as well as of the axial lattice strains of $\{200\} \alpha^{\prime \prime},\{100\} \beta,\{200\} \beta$ and radial $\{200\} \beta$ as a function of strain (Fig. 5a), respectively. The error bars associated with the determination of the lattice strains are comprised within the symbols. A decrease and increase of $\sim 30 \mathrm{vol} \%$ in the volume fractions of $\beta$ and $\alpha^{\prime \prime}$, respectively, takes place from $\sigma \sim$ $700 \mathrm{MPa} / \varepsilon \sim 0.021$ up to $\sigma=930 \mathrm{MPa} / \varepsilon=0.041$, reflecting the previously mentioned stress-induced $\beta \rightarrow \alpha^{\prime \prime}$ transformation during compression of the $\beta$-quenched Ti-5553 alloy.

Fig. 5c) shows that the axial lattice strains of $\{110\} \beta$ and $\{200\} \beta$ $\left(\varepsilon_{\beta \mathrm{A}-110}\right.$ and $\left.\varepsilon_{\beta \mathrm{A}-200}\right)$ gradually increase during the first stage of the deformation up to the onset of the $\beta \rightarrow \alpha^{\prime \prime}$ transformation $(\sigma \sim 700 \mathrm{MPa} / \varepsilon \sim$ $0.021)$. As the deformation increases, $\varepsilon_{\beta \mathrm{A}-110}$ remains practically constant at $\sim-0.01$ up to the maximum stress applied, while $\varepsilon_{\beta \mathrm{A}-200}$ gradually increases to -0.021 at $\varepsilon=0.03$, when a sudden strain drop of $\sim 0.004$ takes place. At this point, the axial lattice strain of $\{200\} \alpha^{\prime \prime}$, $\varepsilon_{\alpha^{\prime \prime} \mathrm{A}-200}$, undergoes a slight increase down to -0.0017 . This suggests a load partitioning between $\alpha^{\prime \prime}$ and $\beta$, considering as well that the planes $\{200\} \alpha^{\prime \prime}$ and $\{200\} \beta$ are parallel according the orientation relationship (OR) $\alpha \square-\beta$ [6]. The strains $\varepsilon_{\beta \mathrm{A}-200}$ and $\varepsilon_{\alpha^{\prime \prime} \mathrm{A}-200}$ decrease at similar rates down to -0.007 and 0.007 during unloading remaining in compressive and tensile state after deformation, respectively. Further examples of load partitioning during stress-induced martensite transformation were reported between austenite-martensite for austenitic stainless- and duplex steels [23].

Fig. 6a) and b) show the evolution of $\{200\} \beta$ and $\{200\} \alpha^{\prime \prime}$ during uniaxial compression and unloading. In most of the cases, $\alpha^{\prime \prime}$ reflections emerge at positions where $\beta$ reflections are present owing to the OR between these lattices. At stresses above the onset of the $\beta \rightarrow \alpha^{\prime \prime}$ transformation, a displacement towards increasing Azimuthal angles for $\{200\} \beta$ and $\{200\} \alpha^{\prime \prime}$ indicate that grain rotation [24] is a relevant deformation mechanism for both phases. Emergence and

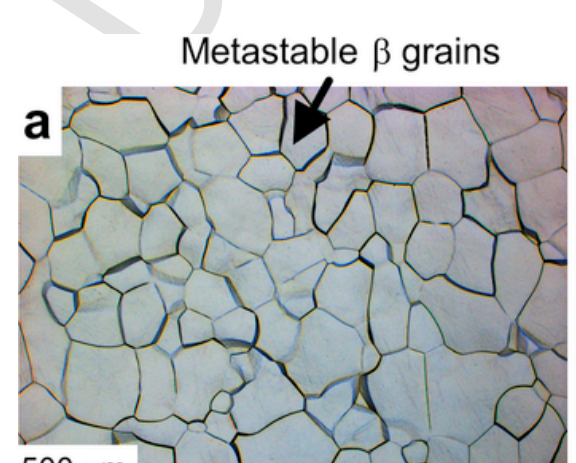

$\omega_{\text {ath }}$ particles
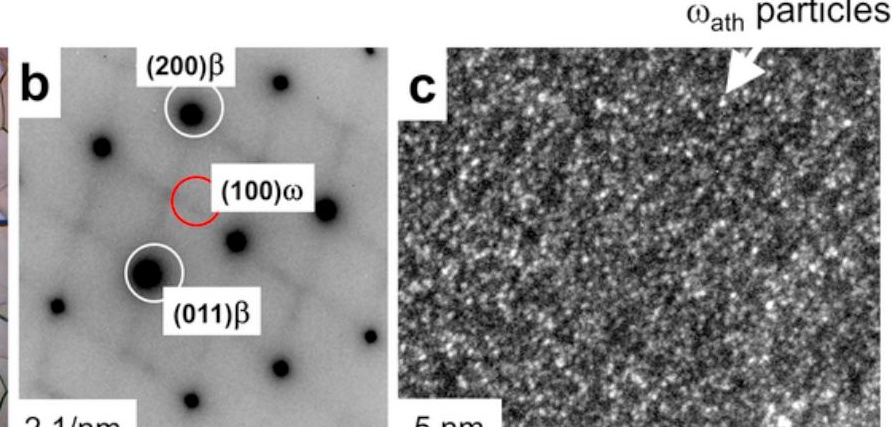

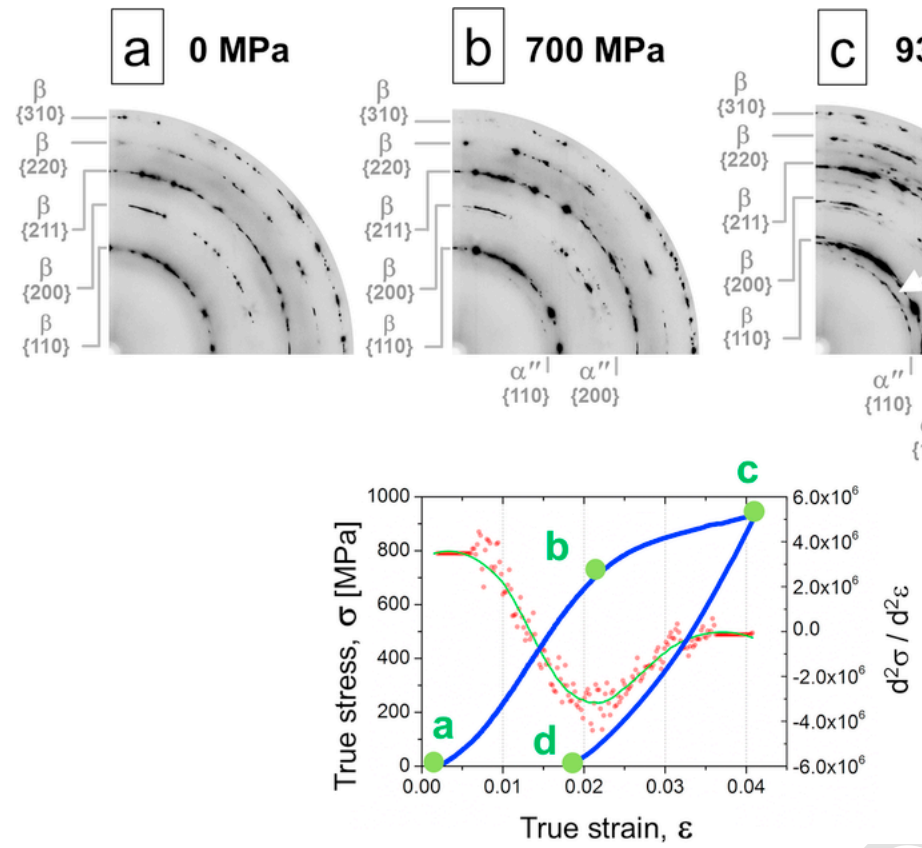
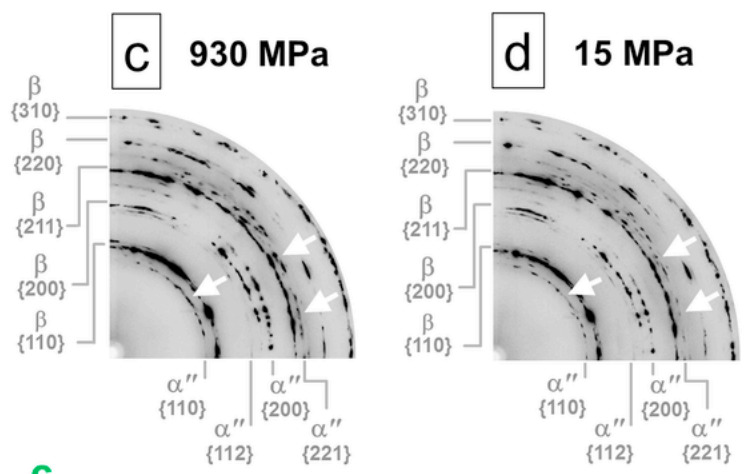

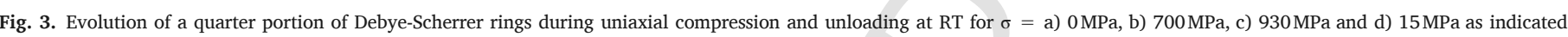

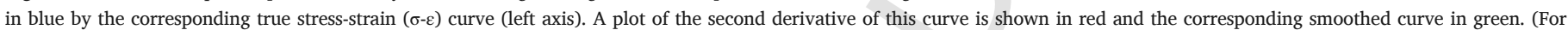
interpretation of the references to color in this figure legend, the reader is referred to the web version of this article.)

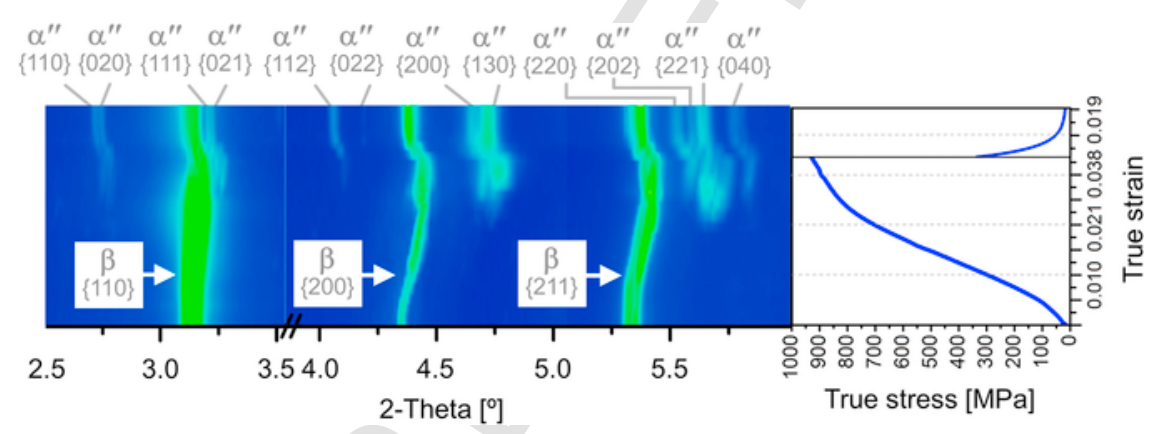

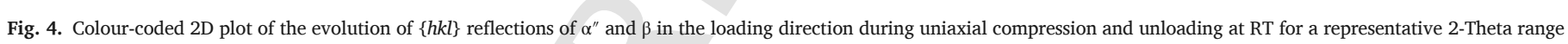
of $2.5-6^{\circ}$

vanishing of specific $\beta$ and $\alpha^{\prime \prime}$ reflections (pointed for few examples by arrows), respectively, can be observed in the unloading stage of the experiment as a consequence of $\alpha^{\prime \prime} \rightarrow \beta$ reversion. The effects described for Fig. 6a) and b) can be visualized in more detail in Fig. 6c) and d), where magnifications of the dashed rectangular regions in Fig. 6a) are shown. The spreading of single $\beta$ spots into cone-shaped reflections observed in Fig. 6c) for $\varepsilon>0.03$, indicate the formation of $\beta$ sub-grain cells [24] as a further mechanism of deformation for this phase. Thus, the sequence of occurrence of plastic deformation mechanisms observed by HEXRD can be summarized as: 1) $\beta \rightarrow \alpha^{\prime \prime}$ transformation plus grain rotation for $\beta$ and $\alpha^{\prime \prime}$ as the yield point is reached, 2) formation of $\beta$ sub-grain cells at $\varepsilon>0.03$. During unloading, 3) partial $\alpha^{\prime \prime} \rightarrow \beta$ reversion takes place in the elastic regime.

\subsection{Microstructure after uniaxial compression}

Fig. 7 shows light optical micrographs of the alloy after uniaxial compression. Slip lines (SL), indicated by white arrows, can be generally observed within $\beta$-grains, mostly extending from their boundaries. Straight SL can extend across $\beta$ grains as can be inferred by its change of orientation (Fig. 7a) and b) at $\beta$ grain boundaries. The interaction of SL with $\beta$ grain boundaries leads to the formation of zig-zag profiles (Fig. 7c). Acicular $\alpha^{\prime \prime}$ martensite plates extending from $\beta$ grain boundaries (GB) can be identified in Fig. 7d), where $\alpha^{\prime \prime}$ units appear partially distorted and twinned between SLs. Probably, they be- long to the same colony since a relatively parallel arrangement between planes and twins is observed. No damage was observed in the microstructure after deformation.

Fig. 8 shows EBSD analyses of the $\beta$ phase for the alloy after deformation. Fig. 8a) shows a forescatter detector image where the SLs described for Fig. 7 are also visible. The inset of this figure shows that martensite can form along SLs. The white domains in Fig. 8b) -d) indicate $\alpha^{\prime \prime}$ martensite regions. The inverse pole figure (IPF) map of Fig. 8b) shows slight misorientations within $\beta$ grains, particularly at SLs (see Fig. 8a). The intra-granular misorientation of $\beta$ can reach up to $\sim 8^{\circ}$ as shown in the quaternion-based colouring misorientation map of Fig. 8d). The black arrows in Fig. 8b) and d) indicates formation of a $\beta$ subgrain. The Kernel average misorientation (KAM) map of Fig. $8 c$ ) shows local misorientations in $\beta$ of $\sim 2.5^{\circ}$ (average misorientations below the subgrain angle) mainly decorating grain boundaries and slip lines. The equivalent KAM map for $\alpha^{\prime \prime}$ provided as Fig. 13 in the Supplementary material shows similar local misorientations of $\sim<$ $2.5^{\circ}$, where regions with minimum and maximum variations are shown in blue and green, respectively.

Fig. 9a) shows the $\alpha^{\prime \prime}$ and $\beta$ phases (in blue and red, respectively) obtained from EBSD analysis of the same region given in Fig. 8. $\alpha^{\prime \prime}$ is usually found close to -or apparently extending from- grain boundaries. The IPF map for $\alpha^{\prime \prime}$ corresponding to the selected region of this figure is presented in Fig. 9b). Here, different colours indicate different variants of martensite colonies within $\beta$ grains, which can present internal strain distributions as shown in the KAM 


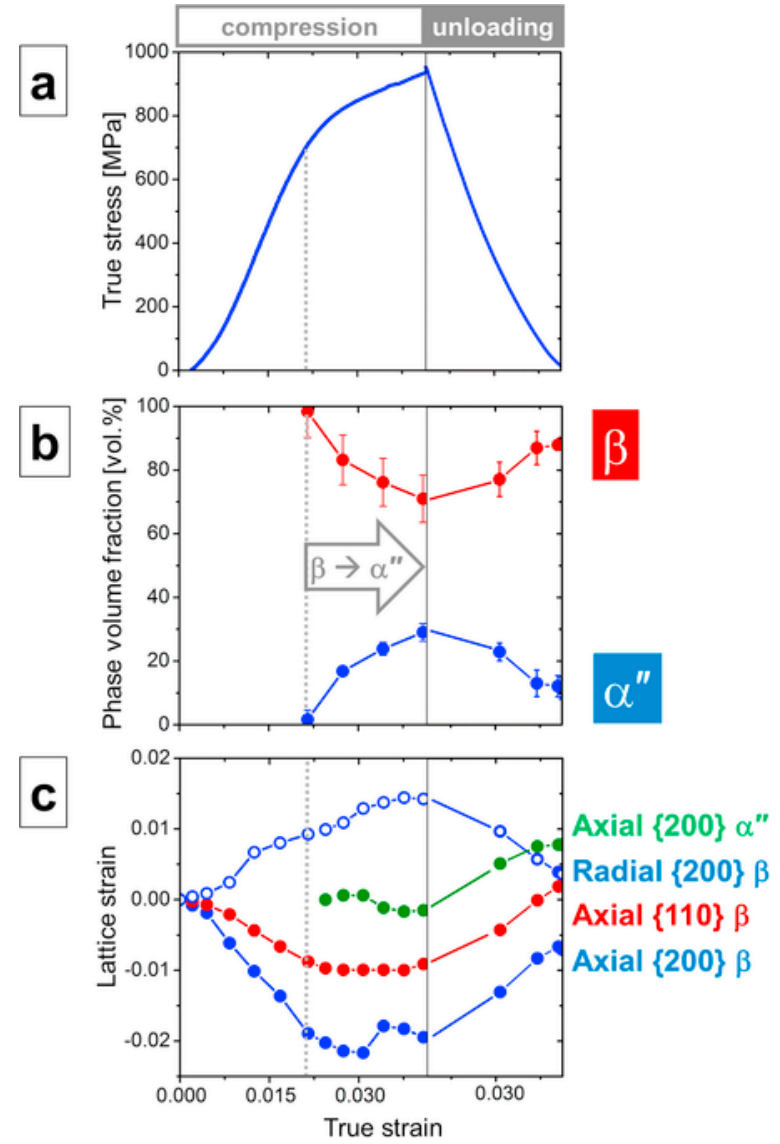

Fig. 5. a) True stress-strain curve, b) evolution of phase volume fractions and c) evolution of characteristic lattice strains of $\alpha^{\prime \prime}$ and $\beta$ phases obtained during uniaxial compression and subsequent unloading.

map of Fig. 9c) for the single colony contained in the framed region of Fig. 9b). The pole figures in Fig. 9d), obtained from the interior of the grain pointed in Fig. 9b) (see arrow), evidence the parallel correlation between $\{100\} \beta / /\{100\} \alpha^{\prime \prime}$ and $\{110\} \beta / /\{010\} \alpha^{\prime \prime} / /\{001\} \alpha^{\prime \prime}$ planes, i.e. a classical OR between these phases as reported for other $\beta$ titanium alloys $[6,25]$. Three different ORs associated with the $\beta \rightarrow \alpha^{\prime \prime}$ transformation were identified in previous studies: (a) (001) $\alpha^{\prime \prime} / /$ (110) $\beta$ and [101] $\alpha^{\prime \prime} / /$ [111] $\beta$, (b) (020) $\alpha^{\prime \prime} / /(11 \overline{2}) \beta$ and [001] $\alpha^{\prime \prime} / /\left[\begin{array}{ll}1 & 1\end{array}\right.$ 0] $\beta$, (c) [100] $\alpha^{\prime \prime} / /$ [100] $\beta$, [010] $\alpha^{\prime \prime} / /$ [101] $\beta$ and [001] $\alpha^{\prime \prime} / /$ [110] $\beta$ [25]. The $\{100\} \alpha^{\prime \prime}$ planes of both variants are parallel and oriented nearly perpendicular to the compression direction. This, together with the alternation of position between $\{010\} \alpha^{\prime \prime}$ and $\{001\} \alpha^{\prime \prime}$ observed for each variant, indicates that there exists a relative rotation of $90^{\circ}$ in the $x$-axis between the $\alpha^{\prime \prime}$ variants.

Fig. 10 shows the pole figures of $\{200\} \alpha^{\prime \prime},\{020\} \alpha^{\prime \prime}$ and $\{002\} \alpha^{\prime \prime}$ reconstructed from the Debye-Scherrer rings acquired by HEXRD after deformation. A strong preferential orientation of $\{200\} \alpha^{\prime \prime}$ planes perpendicular to the compression direction is observed in the bulk of the alloy.

\section{Discussion}

\subsection{Deformation mechanisms of $\beta$}

Stress-induced $\beta \rightarrow \alpha^{\prime \prime}$ transformation takes place during uniaxial compression of the Ti-5553 alloy at $\sigma>700 \mathrm{MPa} / \varepsilon>0.021$, i.e. upon reaching the yield stress of the alloy [22]. This is evidenced in the qualitative as well as quantitative analysis of phase transformation presented as a function of strain in Figs. 3-6. To the best of our knowledge, evidences of this transformation under similar conditions, i.e. low strain rates such as $0.001 \mathrm{~s}^{-1}$, have not yet been reported for this alloy. However, previous works suggested its occurrence from ex situ investigations carried out after extreme deformation processes: high pressure torsion of an analogous Ti-5553 alloy [26], shock-induced deformation of a Ti-5Al-5Mo-5V-3Cr-1Fe alloy $[27,28]$ and high-pressure deformation of a VT-22 alloy [29].

$\beta$-grain rotation begins simultaneously with the $\beta \rightarrow \alpha^{\prime \prime}$ stress-induced transformation (Fig. 6) as the yield point is reached. Both effects coexist up to the maximal applied strain $\varepsilon=0.041$. Thereafter, formation of $\beta$-subgrain cells becomes relevant at $\sigma>800 \mathrm{MPa} / \varepsilon<0.03$ (Fig. 6c). These three deformation mechanisms identified in situ by HEXRD indicate that plasticity in the $\beta$-water quenched alloy is governed by a combination of transformation induced plasticity (TRIP), observed for other $\beta$ metastable alloys [e.g. [10,11,30]], and dislocation-driven plasticity.

According to texture analysis shown in Fig. 10, $\{200\} \alpha^{\prime \prime}$ planes are preferentially oriented perpendicular to the compression direction after deformation. In other words, the $\alpha^{\prime \prime}$ orthorhombic lattice (see crystallographic data in [31]) forms during deformation with its $x$-axis parallel to the compression axis following the classical OR with $\beta$ (Fig. 9d). This is in accordance with the fact that load partitioning is only observed along the axial direction (see Fig. $5 \mathrm{c}$ ), and therefore, $\beta$ grains accordingly oriented i.e. with $\{200\}$ planes perpendicular to the compression axis are expected to undergo preferential stress-induced $\beta \rightarrow \alpha^{\prime \prime}$ transformation during deformation. The resulting texture obtained agrees well with that reported for a near- $\beta$ Ti-5Al-2Sn-4Zr-4Mo-2Cr-1Fe ( $\beta$-CEZ) alloy after tensile testing [32].

The selected KAM map for $\alpha^{\prime \prime}$ of Fig. 9c) (see complete image in Fig. 13 of Supplementary material) shows internal strain distributions (local misorientations of the same magnitude observed for $\beta$ ) within martensite colonies, suggesting that plastic deformation of this phase occurs during compression. Since the highest local misorientations of $\alpha^{\prime \prime}$ (in green) are mainly located next to GBs, these sites may be contemplated as preferred sites for load transfer. This is in accordance with the twinning of martensite plates next to GB observed in Fig. 7d). Owing to the fewer slip systems of the orthorhombic $\alpha$ "structure, accommodation of plastic deformation is more difficult than for the bcc $\beta$-matrix [27].

The dislocation activity is evidenced by the SLs observed within $\beta$-grains (see LOM micrographs of Fig. 7). TEM investigations of the Ti-5553 alloy after compression reveal extensive presence of dislocation channels (DC) as shown in the examples of Fig. 11a) and b), indicating that plastic flow within slip bands is carried by dislocation slip. Slip band interfaces (observed as DCs by TEM) are associated with local stress concentrations [15], seen as green strain-concentrated stripes within the matrix in the KAM map of Fig. 8c). Indeed, KAM values are associated with the density of geometrically necessary dislocations (GNDs) in the investigated region [33]. Planar slip may be influenced by the massive presence of fine $\omega_{\text {ath }}$ particles detected within metastable $\beta$ grains (Fig. 2c) [34].

Thus, continuous formation of dislocation channels leading to dislocation structures that create angular distortions within $\beta$ grains can be expected during compression with increasing plastic strain. Fig. 7 shows different interactions between SL and GBs, namely: (a) SLs in the interior of $\beta$ grains, (b) SLs extending across fragmented $\beta$ grains, as well as (c) formation of GBs with zig-zag profiles. According to previous studies of $\beta$ titanium alloys after deformation [15], the associated microscopic phenomena equivalent to these SL-GB interactions, may be the following: (a) DCs blocked by GBs creating stress concentrations at the DC tip, (b) slip transmission, where a dislocation channel in one grain continues into a connected dislocation channel in the neighbouring grain, and (c) slip along the grain boundary with associated surface relief or trajectory offset of GBs.

Generation of $\beta$ sub-grain cells is revealed by HEXRD during deformation of the Ti-5553 alloy. This effect is a consequence of dislocation slip and can be correlated with EBSD analysis tracing limits of internal misorientation contrast (see arrows in Fig. 8b) and d), and the localized strain along the same limits in the KAM map of Fig. 8c).

The TEM analysis of the deformed condition of the Ti-5553 alloy summarized in Fig. 11c)-e) shows that formation of $\alpha$ " can also take place along dislocation channels. This finding correlates with the 

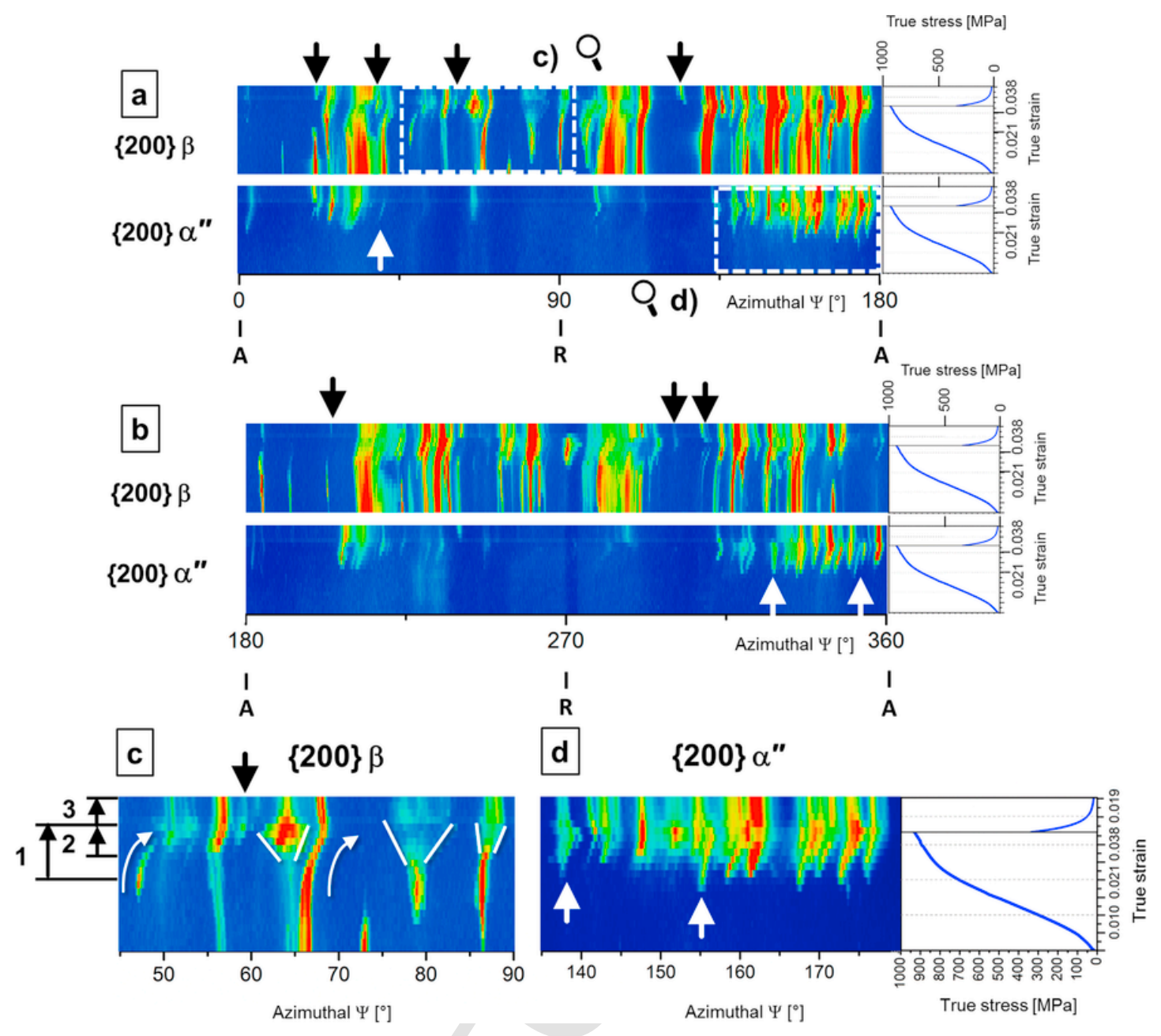

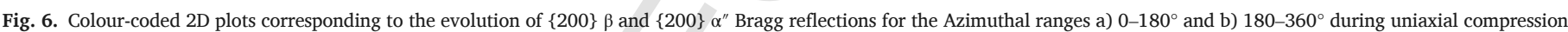

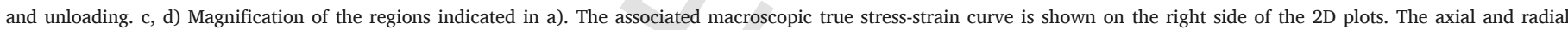
directions are indicated as $A$ and $R$, respectively.

served along SLs revealed by the EBSD investigations shown in the inset of Fig. 8a). Thus, it is suggested that besides GBs, the network of dislocations generated by planar slip within $\beta$ grains can also provide sites for $\alpha^{\prime \prime}$ formation.

\section{2. $\alpha^{\prime \prime} \rightarrow \beta$ reversion}

Partial reversion of $\alpha^{\prime \prime}$ martensite to $\beta$ occurs upon unloading: the volume fraction of $\alpha^{\prime \prime}$ decreases from $\sim 30$ down to $12 \mathrm{vol} \%$ during stress releasing after compression (see Fig. 5b). Evidences of this effect are also pointed qualitatively in Figs. 3 and 6 . In this last figure, the emergence and vanishing of specific $\beta$ and $\alpha^{\prime \prime}$ reflections (see arrows), respectively, can be observed as a consequence of $\alpha^{\prime \prime} \rightarrow \beta$ reversion. It is important to note that some $\beta$ grains form at new orientations, i.e. at Azimuthal positions where reflections of this phase are not present before or during deformation. The $\alpha^{\prime \prime} \rightarrow \beta$ reversion occurs as a displacive transformation driven by the elastic stress relaxation during unloading. It seems reasonable to argue that $\alpha^{\prime \prime}$ units with different degrees of plastic deformation accommodate differently the strain mismatch between $\alpha^{\prime \prime} / \beta$ during unloading.

\subsection{The stability of $\beta$ : the diagram}

The $\overline{B o}-\overline{M d}$ diagram aims at establishing a systematic method for the design of titanium alloys [13]. It is based on the calculation of the alloying parameters $B o$ and $M d$ for bcc $\beta$-Ti: namely, the strength of the covalent bond Ti-alloying metal, and the $d$-orbital energy level of the alloying metal, respectively
$[13,35]$. This diagram reflects an attempt to define the boundaries of different deformation mechanisms as a function of these electronic properties of $\beta$-Ti by using experimental data from a variety of alloying systems $[35,36]$. The average values of these parameters according to the methodology described in [13,37] are the following for the studied Ti-5Al-5V-5Mo-3Cr alloy: $\overline{B o}=2.765, \overline{M d}=2.359$. As shown in Fig. 12 , Ti-5553 is located in the $\alpha+\beta$ field of the $\overline{B o}-\overline{M d}$ diagram (only a representative portion is presented here) close to the $\beta / \alpha+\beta$ border and just below the Ti-10V-2Fe-3Al alloy with $\overline{B o}=2.769, \overline{M d}=2.355$ [13].

Recent investigations proposed an extension of the martensite field (see Fig. 12) based on the deformation mechanisms identified for a $\mathrm{Ti}-10 \mathrm{~V}-3 \mathrm{Fe}-3 \mathrm{Al}$ alloy with respect to the reported behaviour of other alloys [36]. For instance, this alloy stays in the twinning field and presents a combination of martensite and twinning deformation mechanisms. The boundary compositions of the diagram are determined by evaluation of the dominant mechanism of deformation of particular alloys and -although different combinations of these mechanisms are possible- all the alloys are located in one field associated with one mechanism, usually, the dominant one. This is not the case for the water-quenched near- $\beta$ Ti-5553 (this study) and $\beta$-CEZ $(\overline{B o}=2.763, \overline{M d}$ $=2.391$ ) $[32,38]$ alloys which can undergo stress-induced martensite transformation as well as planar slip although they remain in the $\alpha+\beta$ region. Therefore, a reconsideration of the diagram is proposed to extend the martensite- and slip boundaries. Besides the results presented in this work, determination of the new limits needs to be based on more experimental data representing further stability investigations of near- $\beta$ alloys. 


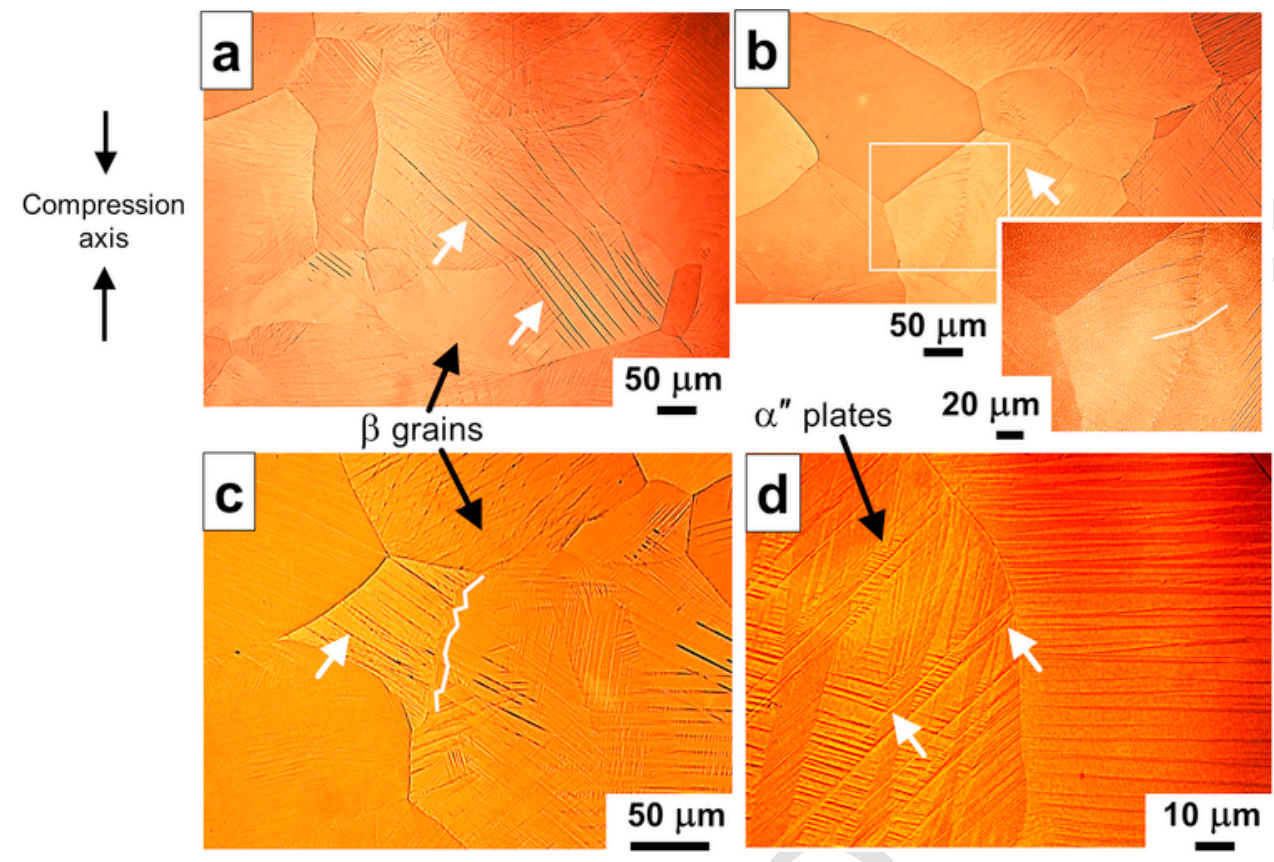

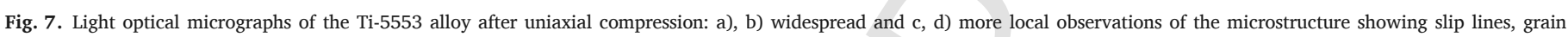
fragmentation and acicular $\alpha^{\prime \prime}$ martensite plates.

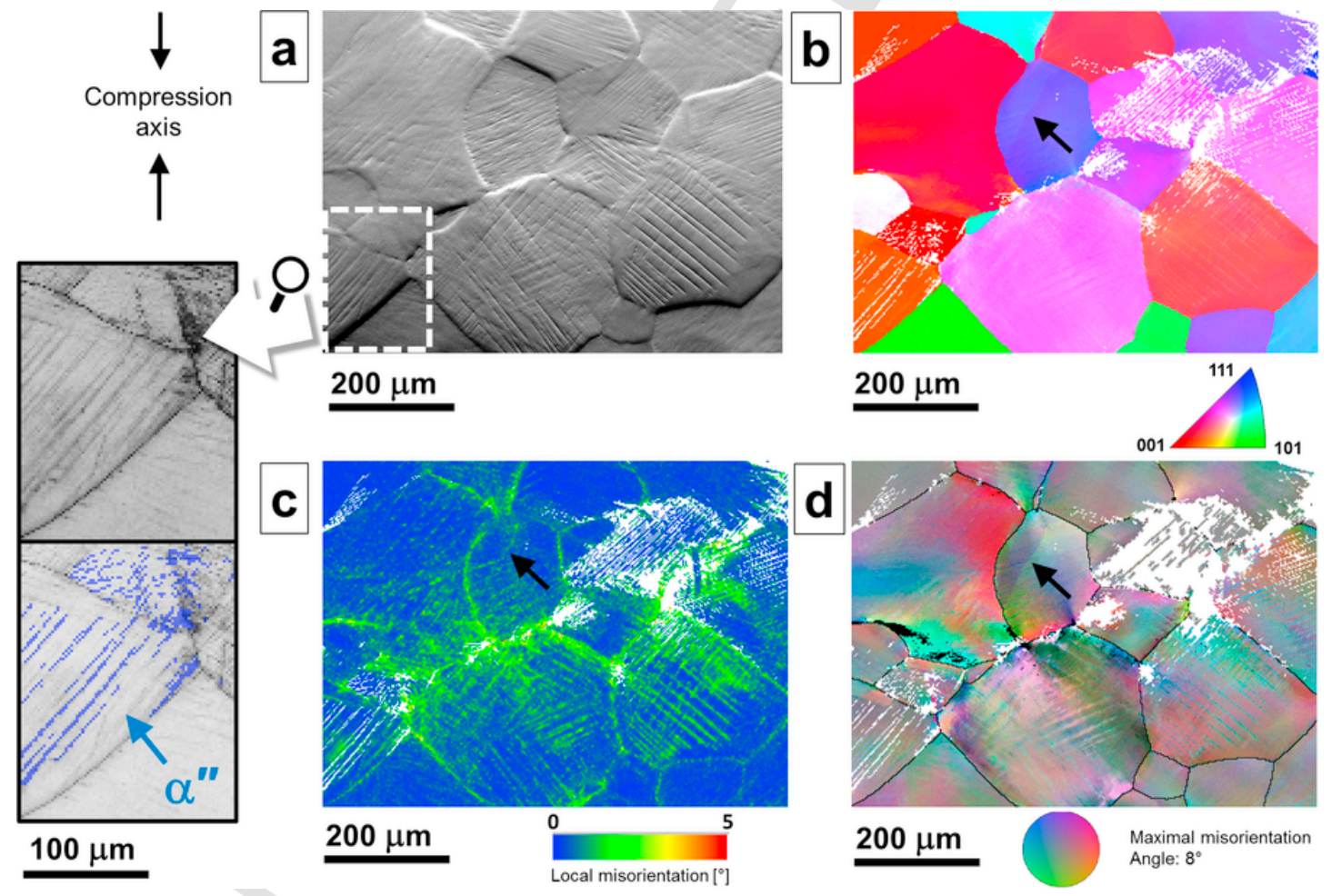

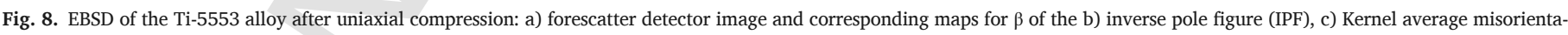

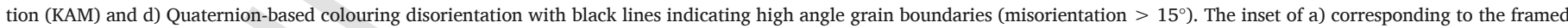
region shows formation of $\alpha^{\prime \prime}$ along slip lines.

\section{Conclusions}

The sequence of deformation mechanisms of a near- $\beta$ Ti-5Al-5Mo-5V-3Cr alloy quenched from the $\beta$-field has been determined in situ as a function of strain during room temperature uniaxial compression at $0.001 \mathrm{~s}^{-1}$ up to $\varepsilon \sim 0.041$, using high energy synchrotron X-ray diffraction (HEXRD) and metallo- graphic analysis. The following conclusions can be drawn from the investigations:

- Stress-induced $\beta \rightarrow \alpha^{\prime \prime}$ transformation and grain rotation of $\beta$ take place simultaneously upon reaching the yield stress of the alloy and coexist up to the maximal strain applied $(\varepsilon \sim 0.041) . \alpha^{\prime \prime}$ martensite forms with a strong variant selection of $\{200\} \alpha^{\prime \prime}$ planes preferentially oriented perpendicular to the 


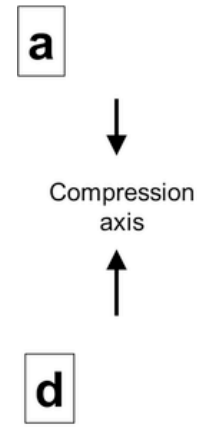

$\{100\} \beta$

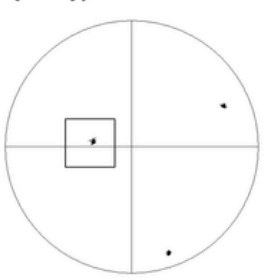

$\{110\} \beta$

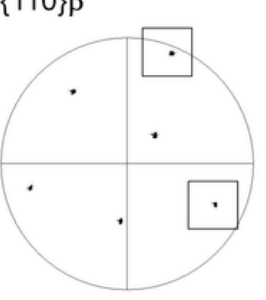

Compression axis
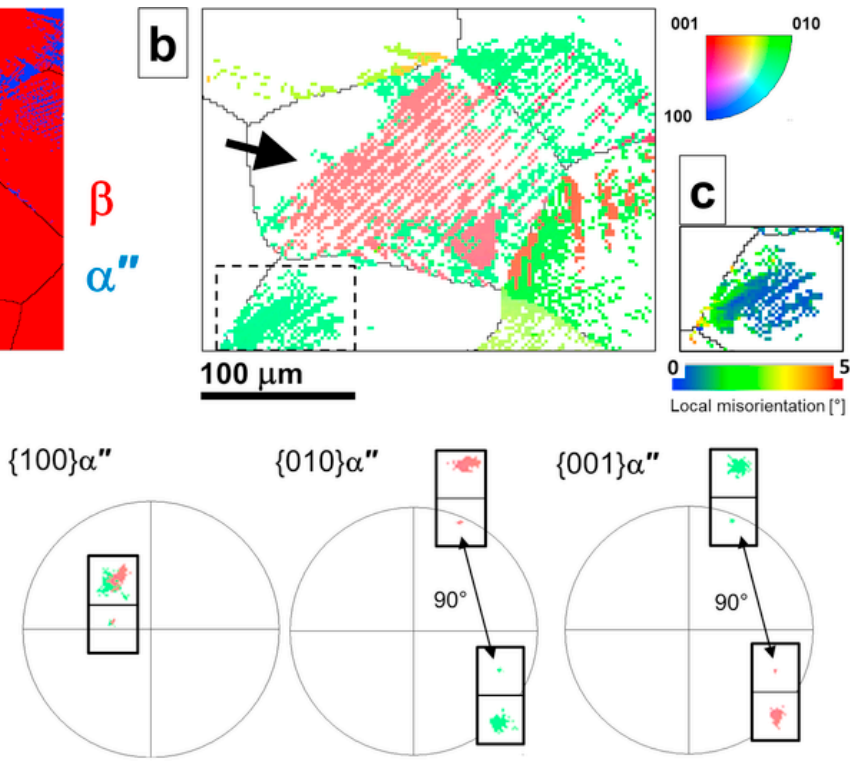

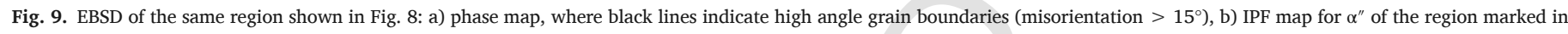

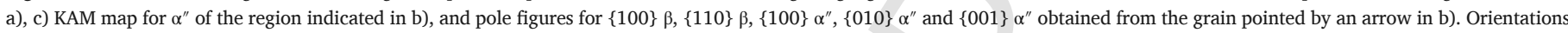

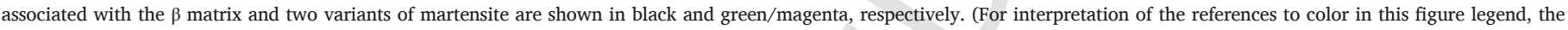
reader is referred to the web version of this article.)

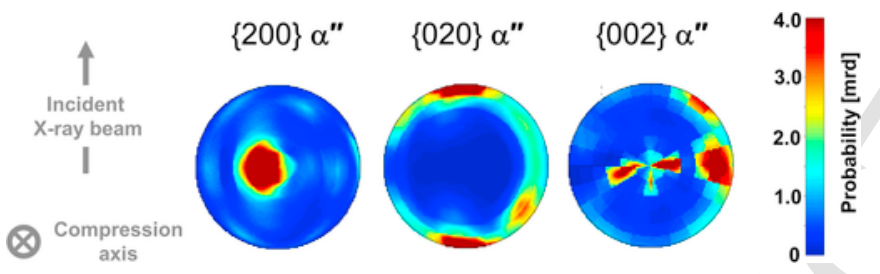

Fig. 10. Pole figures of $\{200\} \alpha^{\prime \prime},\{020\} \alpha^{\prime \prime}$ and $\{002\} \alpha^{\prime \prime}$ reconstructed from the Debye-Scherrer rings acquired by HEXRD after deformation.

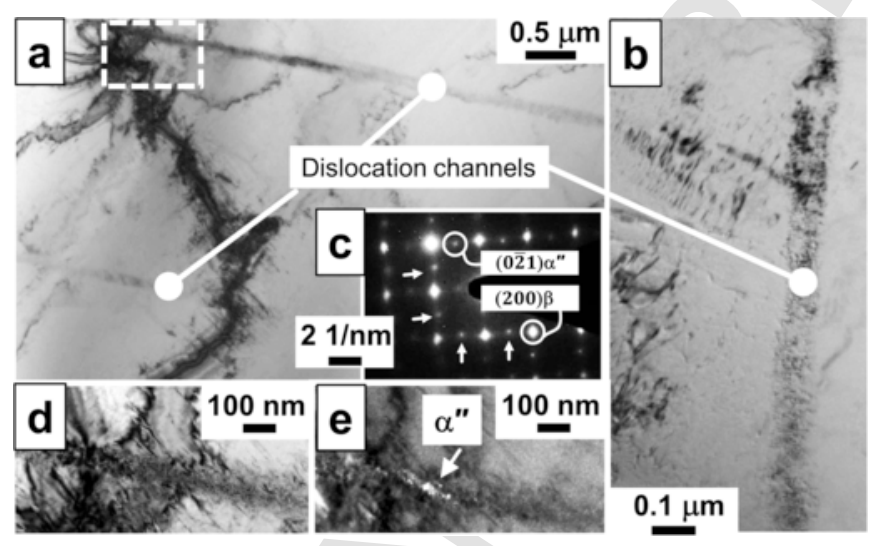

Fig. 11. a) TEM of the initial microstructure of the Ti-5553 alloy after uniaxial compression up to $\varepsilon=0.041$ and subsequent unloading at RT: a), b) bright field images showing dislocation channels, c) electron diffraction pattern of the [100] $\beta$ zone axis taken from the framed region in a) ( $\alpha^{\prime \prime}$ reflections are labelled by arrows), and d) bright field of the framed region in a) with its corresponding dark field image in e) using the encircled ( $0 \overline{2} 1)$ reflection of $\alpha^{\prime \prime}$ indicated in c).

compression direction. Internal strain distributions observed within $\alpha^{\prime \prime}$ colonies indicate that plastic deformation can be also assumed by this phase.

- Dislocation-driven plasticity occurs during compression as revealed by the generalized presence of slip lines within $\beta$-grains observed upon unloading. The extensive presence of dislocation channels or slip band interfaces observed by TEM, indicates that plastic flow carried out by dislocation

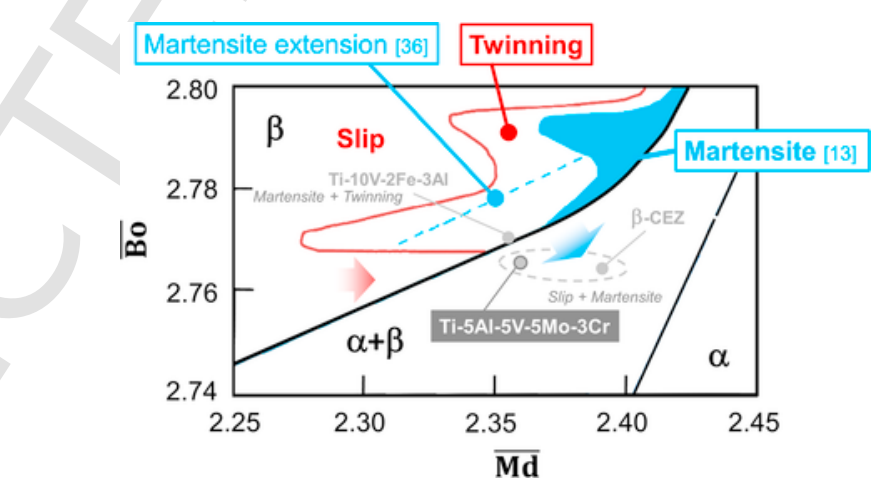

Fig. 12. Portion of the $\overline{\mathrm{Bo}}-\overline{\mathrm{Md}}$ diagram adopted from [13] indicating the modification proposed by [36] and the position of the studied Ti-5553 alloy.

within slip bands. The results show that formation of $\alpha^{\prime \prime}$ can occur along slip lines.

- Formation of $\beta$ sub-grain cells - observed by HEXRD as spreading of single $\beta$ reflections into new Bragg spots - takes place at $\varepsilon \geq 0.03$.

- Load partitioning between $\{200\}$ orientations of $\alpha^{\prime \prime}$ and $\beta$ takes place in the compression direction for $\varepsilon \geq 0.03$.

- Upon unloading, $\alpha^{\prime \prime}$ undergoes a decrease of $\sim 18 \mathrm{vol} \%$ as a consequence of $\alpha^{\prime \prime} \rightarrow \beta$ martensite reversion. This process leads to the formation of new $\beta$ grains that can present different orientations with respect to the originally undeformed $\beta$-matrix.

- The results obtained point to a reconsideration of the deformation mechanisms presented in the $\overline{B o}-\overline{M d}$ diagram for near- $\beta$ alloys. This may imply extension of the martensite- and slip fields.

\section{Acknowledgements}

P. Barriobero-Vila and G. Requena acknowledge the K-Project "Non-destructive testing and tomography Plus" supported by the COMET-Program of the Austrian Research Promotion Agency (FFG) and the provinces of Upper Austria (OÖ) and Styria (St), Grant no. 843540. The Deutsches Elektronen-Synchrotron (DESY) is acknowledged for the provision of synchrotron radiation facilities in the framework of proposal I-20150533 EC. Böhler Schmiede- 
technik GmbH \& Co KG is also acknowledged for the provision of material. The authors would like to thank P. Watermeyer for his support during metallographic analysis.

\section{Appendix A. Supplementary material}

Supplementary data associated with this article can be found in the online version at doi:10.1016/j.msea.2018.01.077.

\section{References}

[1] D. Banerjee, J.C. Williams, Perspectives on titanium and technology, Acta Mater. 61 (2013) 844-879.

[2] D. Eylon, A. Vassel, Y. Combres, R.R. Boyer, P.J. Bania, R.W. Schutz, Issues in the development of beta titanium alloys, JOM 46 (1994) 14-15.

[3] S.L. Nyakana, J.C. Fanning, R.R. Boyer, Quick reference guide for $\beta$ titanium alloys in the 00s, J. Mater. Eng. Perform. 14 (2005) 799-810.

[4] N. Clément, A. Lenain, P.J. Jacques, Mechanical property optimization via microstructural control of new metastable beta titanium alloys, JOM 59 (2007) 50-53.

[5] D. Raabe, B. Sander, M. Friák, D. Ma, J. Neugebauer, Theory-guided bottom-up design of $\beta$-titanium alloys as biomaterials based on first principles calculations: theory and experiments, Acta Mater. 55 (2007) 4475-4487.

[6] P. Barriobero-Vila, V.B. Oliveira, S. Schwarz, T. Buslaps, G. Requena, Tracking the $\alpha$ $\triangle$ martensite decomposition during continuous heating of a Ti-6Al-6V-2Sn alloy, Acta Mater. 135 (2017) 132-143.

[7] F. Sun, J.Y. Zhang, P. Vermaut, D. Choudhuri, T. Alam, A. Mantri, P. Svec, T. Gloriant, P.J. Jacques, R. Banerjee, F. Prima, Strengthening strategy for a ductile metastable $\beta$-titanium alloy using low-temperature aging, Mater. Res. Lett. (2017), (in press).

[8] X.H. Min, K. Tsuzaki, S. Emura, K. Tsuchiya, Enhancement of uniform elongation in high strength Ti-Mo based alloys by combination of deformation modes, Mater. Sci. Eng. A 528 (2011) 4569-4578.

[9] A. Bhattacharjee, V.K. Varma, S.V. Kamat, A.K. Gogia, S. Bhargava, Influence of $\beta$ OV-2Fe-3Al, Metal. Mater. Trans. 37A (2006) 1423-1433.

[10] F. Sun, J.Y. Zhang, M. Marteleur, T. Gloriant, P. Vermaut, D. Laillé, P. Castany, C. Curfs, P.J. Jacques, F. Prima, Investigation of early stage deformation mechanisms in a metastable $\beta$ titanium alloy showing combined twinning-induced plasticity and transformation-induced plasticity effects, Acta Mater. 61 (2013) 6406-6417.

[11] M. Ahmed, D. Wexler, G. Casillas, D.G. Savvakin, E.V. Pereloma, Strain rate dependence of deformation-induced transformation and twinning in a metastable titanium alloy, Acta Mater. 104 (2016) 190-200.

[12] S. Cai, J.E. Schaffer, Y. Ren, Deformation of a Ti-Nb alloy containing $\alpha^{\prime \prime}$-martensite and omega phases, Appl. Phys. Lett. 106 (2015) 1-5, (131907).

[13] M. Morinaga, N. Yukawa, T. Maya, K. Sone, H. Adachi, Theoretical design of titanium alloys, in: Proceedings of the Sixth World Conference on Titanium, 1988, pp. 1601-1606.

[14] S. Neelakantan, E.I. Galindo-Nava, D. San Martin, J. Chao, P.E.J. Rivera-Díaz-del-Castillo, Modelling and design of stress-induced martensite formation in metastable $\beta$ Ti alloys, Mater. Sci. Eng. A 590 (2014) 140-146.

[15] M.J. Lai, C.C. Tasan, D. Raabe, Deformation mechanism of $\omega$-enriched Ti-Nb-based gum metal: dislocation channeling and deformation induced $\omega-\beta$ transformation, Acta Mater. 100 (2015) 290-300.

[16] M.J. Lai, C.C. Tasan, D. Raabe, On the mechanism of $\{332\}$ twinning in metastable $\beta$ titanium alloys, Acta Mater. 111 (2016) 173-186.

[17] P. Barriobero-Vila, G. Requena, S. Schwarz, F. Warchomicka, T. Buslaps, Influence of phase transformation kinetics on the formation of $\alpha$ in a $\beta$-quenched Ti-5Al-5Mo-5V-3Cr-1Zr alloy, Acta Mater. 95 (2015) 90-101.
[18] N. Schell, A. King, F. Beckmann, T. Fischer, M. Müller, A. Schreyer, The high energy materials Beamline (HEMS) at PETRA III, Mater. Sci. Forum 772 (2014) 57-61.

[19] P. Staron, T. Fischer, T. Lippmann, A. Stark, S. Daneshpour, D. Schnubel, E. Uhlmann, R. Gerstenberger, B. Camin, W. Reimers, E. Eidenberger, H. Clemens, N. Huber, A. Schreyer, In situ experiments with synchrotron high-energy X-rays and neutrons, Adv. Eng. Mater. 13 (2011) 658-663.

[20] M.D. Abramoff, P.J. Magalhaes, S.J. Ram SJ, Image processing with imageJ, Biophoton. Int. 11 (2004) 36-41.

[21] L. Lutterotti, S. Matthies, H.R. Wenk, A.J. Schultz, J. Richardson, Combined texture and structure analysis of deformed limestone from time-of-flight neutron diffraction spectra, J. Appl. Phys. 81 (1997) 594-600.

[22] N. Clément A. Lenain P.J. Jacques Comparison of the microstructure and mechanical properties of the metastable beta titanium alloys Ti-LCB and Ti-555 in: M. Ninomi S. Akiyama M. Ikeda M. Hagiwara K. Maruyama (Eds.), Ti-2007 Science and Technology: Proceedings of the 11th World Conference on Titanium The Japan Institute of Metals 2007 pp 495-498

[23] P. Hedström, L.E. Lindgren, J. Almer, U. Lienert, J. Bernier, M. Terner, M. Odén, Load partitioning and strain-induced martensite formation during tensile loading of a metastable austenitic stainless steel, Metal. Mater. Trans. A 40A (2009) 1039-1048.

[24] K.-D. Liss, K. Yan, Thermo-mechanical processing in a synchrotron beamline, Mater. Sci. Eng. A 528 (2010) 11-27.

[25] M. Ahmed, A.A. Gazdier, A.A. Saleh, D. Wexler, E.V. Pereloma, Stress-induced twinning and phase Transformations during the compression of a Ti-10V-3Fe-3Al Alloy, Metall. Mater. Trans. A 48 (2017) 2791-2800.

[26] A. Zafari X.S. Wei W. Xu K. Xia Effects of severe plastic deformation on grain refinement and martensitic transformation in a metastable $\beta$ Ti alloy IOP Conf. Ser.: Mater. Sci. Eng. 89 (2015) 1-7 (012055)

[27] X. Xu, L. Wang, D. Zhao, W. Du, Dynamic behavior in Ti-5553 alloy with $\beta$ phase under compression loading, Appl. Mech. Mater. 782 (2015) 88-96.

[28] L. Wang, Y..Wang, X. Xu, C. Liu, Dynamic behaviour and shock-induced martensite transformation in near-beta Ti-5553 alloy under high strain rate loading, EPJ Web of Conferences, vol. 94, 2015 , pp. 1-4. (02026).

[29] T.O. Ryumshyna, H.K. Volkova, L.V. Loladze, T.E. Konstantinova, Evolution of the structure of Ti-5Al-5Mo-5V alloy deformed by high pressure, Mater. Sci. 42 (2006) 344-352.

[30] M. Marteleur, F. Sun, T. Gloriant, P. Vermaut, P.J. Jacques, F. Prima, On the design of new $\beta$-metastable titanium alloys with improved work hardening rate thanks to simultaneous TRIP and TWIP effects, Scr. Mater. 66 (2012) 749-752.

[31] P. Barriobero-Vila, G. Requena, F. Warchomicka, A. Stark, N. Schell, T. Buslaps, Phase transformation kinetics during continuous heating of a $\beta$-quenched Ti-10V-2Fe-3Al alloy, J. Mater. Sci. 50 (2015) 1412-1426.

[32] D. Pionner, M. Humbert, M.J. Philippe, Y. Combres, Study of the $\alpha^{\prime \prime}$ phase texture obtained by martensitic $\beta-\alpha$ " phase transformation induced by tensile test in a sheet of Ti-5Al-2Sn-4Zr-4Mo-2Cr-1Fe, Acta Mater. 46 (1998) 5891-5898.

[33] Z. Li, C.C. Tasan, K.G. Pradeep, D. Raabe, A TRIP-assisted dual-phase high-entropy alloy, grain size and phase fraction effects on deformation behavior, Acta Mater. 131 (2017) 323-335.

[34] J. Huang, Z. Wang, J. Zhou, Cyclic deformation response of $\beta$-annealed Ti-5Al-5V-5Mo-3Cr alloy Under compressive loading conditions, Metal. Mater. Trans. A 42 (2011) 2868-2880.

[35] D. Kuroda, M. Niinomi, M. Morinaga, Y. Kato, T. Yashiro, Design and mechanical properties of new $\beta$ type titanium alloys for implant materials, Mater. Sci. Eng. A 243 (1998) 244-249.

[36] M. Ahmed, D. Wexler, G. Casillas, O.M. Ivasishin, E.P. Pereloma, The influence of $\beta$ phase stability on deformation mode and compressive mechanical properties of Ti-10V-3Fe-3Al alloy, Acta Mater. 84 (2015) 124-135.

[37] M. Abdel-Hady, K. Hinoshita, M. Morinaga, General approach to phase stability and elstic properties of $\beta$-type Ti-alloys using electronic parameters, Scr. Mater. 55 (2006) 477-480.

[38] T. Grosdidier, C. Roubaud, M.-J. Philippe, Y. Combres, The deformation mechanisms in the $\beta$-metastable $\beta$-CEZ titanium alloy, Scr. Mater. 36 (1997) 21-28. 
Appendix A. Supplementary material

Multimedia Component 1

Fig. S1. EBSD-KAM map for $\alpha^{\prime \prime}$ of the initial microstructure of the Ti-5553 alloy after uniaxial compression up to $\varepsilon=0.041$ and subsequent unloading at RT. Black lines indicate high angle grain boundaries (misorientation $>15^{\circ}$ ). 